\title{
NUESTROS ANCESTROS LOS GALOS. EUGÈNE SUE Y LOS MISTERIOS DEL PUEBLO FRANCÉS
}

\author{
OUR ANCESTORS THE GAULS. \\ EUĠ̀NE SUE AND THE MYSTERIES OF THE FRENCH PEOPLE \\ Raquel Sánchez* \\ Universidad Complutense de Madrid-España
}

\begin{abstract}
RESUMEN: La novela popular del siglo XIX jugó un papel muy importante en la creación de imaginarios políticos y sociales. Les mystères du peuple, de Eugène Sue, es uno de los mejores ejemplos de ello. Ideológicamente inserta en el romanticismo social, la novela propone, por un lado, una lectura del pasado francés que difiere de la ofrecida por otras interpretaciones coetáneas; por otro lado, lleva a cabo un análisis de la realidad en la que el conflicto entre clases es la clave explicativa de la historia. Sus ideas se proyectaron en el discurso republicano de las décadas posteriores, despojadas del romanticismo socialista defendido por su autor.

PALABRAS CLAVE: Francia; Nacionalismo francés; Romanticismo social; Socialismo premarxista; Eugène Sue; Literatura.

ABSTRACT: The popular novel played a very important role in the creation of political and social imaginaries in the nineteenth century, being Eugène Sue's Les mystères du peuple one of the best examples of it. Ideologically close to social romanticism, the novel proposes, on one hand, an interpretation of the French past that differs from that offered by other coetaneous analysis. On the other hand, it carries out an analysis of social reality in which the conflict between classes is the explanatory key of history. Sue's ideas were projected in the republican discourse of the following decades, stripped of the socialist romanticism defended by its author.
\end{abstract}

KEYWORDS: France; French Nationalism; Social Romanticism; Pre-Marxist Socialism; Eugène Sue; Literature.

* Correspondencia a / Corresponding author: Raquel Sánchez. Universidad Complutense. Departamento de Historia Moderna e Historia Contemporánea. Facultad de Geografía e Historia, Edificio B. C/ Profesor Aranguren s/n. 28040, Madrid, (España) - raquelsg@ucm.es - https://orcid.org/0000-0001-8256-9695

Cómo citar / How to cite: Sánchez, Raquel (2022). "Nuestros ancestros los galos. Eugène Sue y los misterios del pueblo francés», Historia Contemporánea, 68, 49-78. (https://doi.org/10.1387/hc.21469).

Recibido: 21 enero, 2020; aceptado: 27 abril, 2020.

ISSN 1130-2402 - elSSN 2340-0277 / ㄷ 2022 Historia Contemporánea (UPV/EHU) 
A lo largo del siglo XIX, y en particular durante el romanticismo, la literatura popular participó muy activamente en la construcción del imaginario nacional, ya que facilitó el acceso a un discurso identitario -en el que se mezclaba el relato novelesco con el mensaje político- a todo tipo de públicos, desde la aristocracia hasta las clases medias y populares. El proceso presentó claras similitudes en toda Europa, de ahí que resulte llamativo que un movimiento como el romanticismo, obsesionado con la recuperación de lo propio, lo único, lo original, se sirviera de recursos transnacionales a la hora de crear unos referentes en los que la comunidad política podía encontrar un reflejo de lo que fue, de lo que era en ese momento y de lo que podía llegar a ser. Poesías, canciones, novelas, obras teatrales... se llenaron en toda Europa de héroes del pasado y del presente, de batallas y de epopeyas grandiosas o cotidianas, que se encarnaban en individuos a los que el lector se acercaba a través de un lenguaje pensado para mover a la emoción ${ }^{1}$. Se repitieron esquemas narrativos, efectos literarios, estereotipos humanos y formas de comercialización en todo el continente. Gran Bretaña y Francia fueron países pioneros a este respecto en los que, además de unas creaciones de carácter nacionalista más o menos explícito, el romanticismo social encontró una vía perfecta para la evidenciar las injusticias que se estaban produciendo con la modernización económica impulsada por la industrialización.

En el caso de Francia, los círculos vinculados al romanticismo social, al republicanismo de izquierdas y al socialismo utópico se sirvieron de la literatura popular para concienciar políticamente a la población, teniendo siempre como referente la revolución de 1789, en toda su pluralidad de manifestaciones. Eugène Sue fue uno de los pilares de este romanticismo social y literario. Nacido en París en 1804, estudió medicina y pasó una parte de su juventud trabajando como médico en la armada. Tras la muerte de su padre en 1830, abandonó el mar para vivir de la herencia familiar, convirtiéndose en un dandi frecuentador de salones y fiestas, por lo que fue conocido como «le Beau Sue». A la vez, escribía novelas de ambiente marino (Kernok le pirate, Plick et Plock) y recreaciones históricas (Latréaumont, Jean Cavalier). Cuando la fortuna familiar se agotó, decidió dedicarse profesionalmente a la literatura y al periodismo. Comenzó a colaborar en La Presse, Le Constitutionnel y Le Journal des Débats y siguió publicando novelas en las que reproducía el entorno social

\footnotetext{
${ }^{1}$ Una visión global de este proceso en Thiesse, 2010.
} 
que había conocido en su vida de joven rico y ocioso. Entre 1840 y 1841 entró en contacto con los entornos proletarios de París, lo que le hizo tomar conciencia de la situación de las clases trabajadoras. A partir de ese momento, el dandi Sue se convirtió en un escritor dedicado a la denuncia de las injusticias sociales, como demostró con la publicación en Le Journal des Débats de la novela que le catapultaría al éxito: Les mystères de Paris (1842-1843). Detrás de esta obra vendrían otras muchas en las que Sue evidenció su escoramiento ideológico hacia las filas del republicanismo socialista. Tras la revolución de 1848 fue elegido diputado por París, pero tras el golpe de Louis Napoléon Bonaparte en 1851 tuvo que salir al exilio a Annecy (Saboya italiana), desde donde siguió escribiendo novelas de un contenido social muy marcado. Murió en 1857, a los cincuenta y tres años ${ }^{2}$.

\section{Sue y la censura política durante el Segundo Imperio}

Fue precisamente a partir la revolución de 1848 cuando Sue se lanzó a la escritura de la que iba a ser su última obra, una larga novela que se encuadra, como casi todas las suyas, en el género del folletín, la llamada en la época «literatura industrial». Se trata de Les mystères du peuple, cuyo muy ilustrativo subtítulo responde claramente a los principios ideológicos defendidos por el autor: Histoire d'une famille de prolétaires à travers les âges. Sin embargo, Les mystères du peuple no es solo una novela políticamente significada a la izquierda, sino que en sus páginas el lector encuentra también una interpretación de la historia de Francia marcada por el enfrentamiento entre dos grupos sociales, los opresores y los oprimidos, que además se corresponden con dos razas enfrentadas: la Francia auténtica y la Francia impostada; la Francia gala y la Francia de origen franco. Les mystères du peuple también es, por tanto, una obra fuertemente nacionalista. De gran éxito en su tiempo, la posteridad no le ha reservado el lugar destacado que han gozado otras obras de su autor, siendo definida por algún especialista como una especie de «catecismo alucinado» de la historia proletaria de Francia $^{3}$. Si bien esta apreciación es un tanto exagerada, no deja de tener un punto de razón en tanto que Sue no oculta en ninguno de sus dieciséis volú-

2 Thiesse, 1980; Bory, 1973; Garay, 2021.

3 Amalvi, 1989, p. 590. 
menes su intención militante, siguiendo la estela del poeta-profeta tan querida al romanticismo en cualquiera de sus manifestaciones ${ }^{4}$.

El editor Maurice Lachâtre comenzó a publicar la novela en 1849 a través del sistema de suscripciones, que era la mejor forma de acercarse al lector popular pues, según sus palabras, «les pauvres ne peuvent pas payer la science qu'avec l'obole» ${ }^{5}$. No es casualidad que fuera Lachâtre el editor de esta novela de Sue, de quien era amigo cercano. Hijo de un barón de profesión militar, Maurice Lachâtre abandonó pronto el hogar familiar y se unió a la escuela saint-simoniana. Después de varias peripecias profesionales, entre las que se incluyen la creación de un centro escolar y una casa bancaria, recaló en el mundo editorial aprovechando el amplio campo que se abría para los empresarios del libro con la modernización técnica del sector y con la ampliación del público. A él se deben algunos de los éxitos editoriales de Alexandre Dumas, como sus Crimes célèbres, aparecidos en los inicios de la década de los cuarenta. Amigo de Proudhon, la evolución ideológica de Lachâtre le condujo a aproximarse al fourierismo y, con los años, al anarquismo y al espiritismo. De hecho, uno de sus colaboradores fue el famoso médium Allan Kardec. Deseoso de ver en la realidad las ideas que defendía, puso en marcha un proyecto político-social mutualista en la propiedad que había adquirido en Arbanats, en la región de la Gironde. Lachâtre sufrió varios procesos judiciales y el exilio por el contenido de algunas de sus publicaciones, aunque el caso más sonado fue, precisamente, el de Les mystères $d u$ peuple, como veremos en breve. Fue también el editor de Louis Blanc (Histoire de la Révolution française), de Ferdinand Lassalle (Capital et travail), de la primera edición francesa del más célebre trabajo de Marx, Le Capital, etc. ${ }^{6}$

Les mystères du peuple siguieron apareciendo con el mismo formato hasta su número final en 1857, con ilustraciones que se enviaban a los suscriptores. Sue empleó, por tanto, ocho años en terminar la novela. Aunque toda ella tiene un contenido político claro, es en los volúmenes primero y último en los que esta realidad se hace más patente. A pesar de haberse publicado en dos momentos muy distintos, las consecuencias de la aparición del primer y último volumen fueron muy parecidas. El primero se editó en

${ }^{4}$ Sobre la figura del poeta-profeta, véase el clásico libro de Bénichou (1981).

5 Thiesse, 1990, p. 514.

${ }^{6}$ Cahen, 2011. Lachâtre fue, además, muy conocido por su marcado anticlericalismo, sobre todo a raíz de la aparición de su libro Histoire des Papes. Mystères d'iniquités de la cour de Rome, publicado entre 1842 y 1843, que conoció varias reediciones. Sobre él, Gaudin, 2014. 
1849. La revolución de 1848 acababa de finalizar, pero aún no se había consolidado el proceso de centralización del poder en manos de Louis Napoléon Bonaparte. Sin embargo, tras el golpe de estado de 2 de diciembre de 1851, autor y editor fueron perseguidos, hasta el punto de que Sue tuvo que huir a la Saboya italiana ante la amenaza de arresto. Por otra parte, la publicación de la obra se vio interrumpida entre diciembre de 1851 y junio de 1853 , lo que perjudicó enormemente a editor y autor a causa de la anulación de las suscripciones y la pérdida de ingresos ${ }^{7}$. Además, y como tantas novelas populares, el texto de Sue se vio afectado por la ley Riancey, promulgada en 1851, por la que se tasaba con cinco céntimos a los periódicos que publicaran novelas por entregas, mostrando el carácter políticamente sospechoso de estas. Por las mismas fechas, la obra, además, recibió el rechazo de la historiografía conservadora, acusando a su autor de haber roto el consenso sobre el pasado histórico del país ${ }^{8}$.

El último volumen vio la luz en 1857, cuando el Segundo Imperio se hallaba en su apogeo autoritario, con una fuerte represión de las libertades, en particular, las de expresión y prensa. Un libro, este último volumen, que dirigía acusaciones muy directas no solo a Napoléon III, sino también a su tío, imputándoles a ambos el fracaso de las revoluciones liberales que había vivido el país. En ese mismo año de 1857, entre enero y febrero, habían tenido lugar los procesos contra Gustave Flaubert y Charles Baudelaire por la publicación de Madame Bovary y Les fleurs $d u$ mal. El ambiente, por tanto, no era muy propicio para la aparición de obras consideradas inmorales o subversivas, pese a lo cual, Lachâtre decidió continuar dando a la imprenta los fascículos de Sue. Poco después de la impresión del último de ellos, se inició el proceso contra el autor, que murió en agosto de 1857, en pleno desarrollo de las pesquisas judiciales. En el proceso que se siguió contra él, la Cour Impérial de París acusaba a Eugène Sue de ultraje a la moral pública y religiosa, de incitación al odio entre los ciudadanos, de apología de varios delitos, de levantar al pueblo en contra del gobierno y de atacar el derecho de propiedad «dans chaque volumen, à chaque page» ${ }^{9}$. Aunque al autor solo se le podía condenar verbalmente, el tribunal no se privó de dejar constancia de la mancha que el

7 Bory, 1973, pp. 352 y 363.

8 Wautier d'Halluvin, 1851.

9 El proceso se publicó en La Gazette des Tribunaux el 25 de septiembre de 1857. Puede consultarse en http://eugene.sue.free.fr/les_peuple.html Un análisis de los tres procesos (Baudelaire, Flaubert y Sue) en Pierrat, 2010. El fiscal que persiguió a estas tres 
escritor dejaba sobre las personas próximas a él, quienes iban a sufrir una «profonde affliction» por su inmoralidad. Se trataba, sobre todo, de insistir en el carácter disolvente y en la «perversité systématique» de sus escritos. La sentencia definitiva condenó a Lachâtre y a los impresores de la obra a un año de cárcel y al pago de los gastos judiciales y puso un especial énfasis en la destrucción de los clichés de imprenta y de todos los ejemplares que quedaran de la obra.

Pese a todas estas prohibiciones, la novela continuó circulando de forma clandestina hasta la dimisión del general MacMahon en 1879 y, por tanto, la consolidación de la Tercera República en Francia. A partir de ese momento, se pudo publicar libremente ${ }^{10}$. Además, y dado que Sue no pudo cumplir su promesa de continuar la obra a causa de su fallecimiento ${ }^{11}$, el editor Lachâtre contrató al escritor republicano Hector France para continuar la novela, lo que daría como resultado la publicación en 1898 de Les Mystères du monde, suite et fin des Mystères du peuple.

\section{Los misterios del pueblo francés}

¿Qué historia se narraba en esta larga novela que tanto preocupaba a la censura imperial? Partiendo de los momentos previos al estallido de la revolución de febrero de 1848, Sue plantea su relato en torno a la historia de una familia, los Lebrenn, de origen bretón, que son los protagonistas del relato y la encarnación de la Francia trabajadora y emprendedora, es decir, de los proletarios y de los pequeños burgueses. Frente a ellos están los Plouernel, descendientes de una familia de origen franco, que simbolizan a la vieja aristocracia legitimista, parasitaria, clerical e improductiva. Al final del primer volumen el relato va hacia atrás en el tiempo para remontarse a la ocupación romana de la Galia, momento en que el lector conoce a los antepasados de los Lebrenn. A partir de ahí, Sue va haciendo

obras literarias fue el mismo: Ernest Pinard, de acendradas creencias católicas y ferviente bonapartista.

${ }^{10}$ La novela había sido prohibida también en Austria, Rusia, Prusia y varios estados italianos. Pese a las dificultades, en 1857 Giuseppe Mazzini publicó una nueva edición de la misma en Suiza (Bory, 1973, 353 y 401). Según los cálculos realizados, entre 1849 y 1850 tuvo cuatro ediciones en Francia, con una tirada que, en conjunto, pudo alcanzar los 20.000 ejemplares (Lyons, 1990, p. 423).

11 Sue, 1857, XVI, p. 399. 
un recorrido por la historia del país sirviéndose de los miembros de esta familia y, cuando se produce la irrupción de los francos, de los Plouernel. Entendida como la lucha entre los opresores y los oprimidos, la historia de Francia es presentada como un proceso largo y violento que persigue un único destino: la democracia republicana apoyada en la soberanía popular. El último volumen se centra en una etapa histórica fundamental del relato: la Francia contemporánea, desde 1789 hasta 1849, época crítica en la que la consecución del gran proyecto de liberación del pueblo parece acelerarse hasta la resaca que siguió a los acontecimientos de 1848. La novela ha de leerse en ese contexto del 48, ya que explica la historia de Francia desde una perspectiva claramente teleológica, orientada hacia la liberación final de los oprimidos ${ }^{12}$.

Precisamente por esa finalidad a la vez pedagógica y política, la novela mantiene una alternancia entre el relato novelesco y la narración histórica. Esta obra es un buen ejemplo de la porosidad de las fronteras entre escritura literaria y escritura histórica en tanto que ambas estrategias narrativas, que parten de presupuestos diferentes, confluyen en un espacio común: la novela sentimental con finalidad política ${ }^{13}$. Sue construye una ficción literaria que pretende presentarse ante el lector como la historia verdadera de Francia. Si en Les mystères de Paris quería mostrar esa otra ciudad, desconocida para la mayoría, velada a los ojos de los biempensantes - el París de la marginación y la pobreza- en Les mystères du peuple ofrece a sus lectores la otra historia de Francia. En realidad, la verdadera historia de Francia, ocultada a los ciudadanos por una conspiración clerical y aristocrática de los poderosos que han llevado las riendas del país hasta 1789, momento en que el gran engaño fue desvelado. La verdadera historia de Francia es la de los desposeídos, la mayoría de la población y la raíz del pueblo francés porque, históricamente, constituyen la población originaria. Volveremos sobre ello. Para dar más verosimilitud a su relato, Sue combina los diálogos y las descripciones de sus personajes y los espacios por los que se mueven con notas al pie en las que da detalles, a veces eruditos, acerca de nombres galos, romanos o francos; información histórica sobre

12 Levêque, 2014; y s.f., p. 113.

13 Véanse al respecto las reflexiones de Burdiel y Serna (1996), Charle (2009) y LyonCaen y Ribard (2010). Una exposición general sobre las teorías que explican la relación entre historia y literatura en Lillo (2017). Los trabajos de Judith Lyon-Caen sobre los autores de novela popular en la Francia del siglo XIX son un buen ejemplo práctico de las problemáticas que se derivan de este tipo de análisis $(2006,2009)$. 
determinados personajes; datos sobre ciertas costumbres antiguas; etc. En algunos casos, incluso, se cita bibliografía, apoyando de este modo la información proporcionada con el respaldo académico especializado ${ }^{14}$. En otras ocasiones, y de nuevo con el objetivo de apoyar históricamente la narración, incluye fragmentos de documentos sobre acontecimientos especialmente relevantes, como las crónicas medievales, el proceso a Juana de Arco o la transcripción de los debates en la Asamblea nacional durante el periodo revolucionario. También se sirve de esta documentación para reproducir conversaciones entre personajes históricos. Se trata de conversaciones ficticias, pero respaldadas por obras historiográficas conocidas, haciendo revivir ante los ojos de los lectores a personajes conocidos por ellos como César, Clodoveo, Enrique IV, Luis XV, etc.

La parte novelesca de Les mystères du peuple se apoya en la evolución de la dinastía Lebrenn a lo largo de la historia a través de una trama en la que lo verosímil presenta bastantes debilidades. Aunque, editorialmente hablando, no apareció primeramente como la mayoría de las novelas de folletín en los faldones de los periódicos, sino en forma de fascículos, los recursos utilizados por Sue responden plenamente al género: escritura rápida, improvisación, cambio de ambientes, mezcla de personajes reales con caracteres ficticios, efectismo, uso del suspense, frecuentes incoherencias en la trama, etc. ${ }^{15}$ Dado que la obra persigue un fin sociopolítico claramente definido desde el primer tomo, los Lebrenn aparecen siempre, de una forma o de otra, en los acontecimientos más significativos del pueblo francés, desempeñando papeles diversos. En unas ocasiones, como comparsas de los personajes históricos, sirviendo de soporte para que estos últimos puedan hacerse presentes de una forma creíble ante el lector y, en la mayoría de los casos, a través de pequeños gestos heroicos que constituyen la lucha del pueblo francés anónimo, gestos que no aparecen en los libros de historia, pero sin los cuales Francia no habría mantenido el testigo de la lucha contra la opresión. El paralelismo entre la «gran historia» y la «pequeña historia» del pueblo francés se evidencia también al documentar esta última, pues el autor se sirve de los apuntes escritos

${ }^{14}$ Sue cita, entre otros, a Augustin Thierry, Histoire de la conquête de l'Anglaterre par les Normands y Récits des temps des Mérovingiens; La Tour de l'Auvergne, Origines Gauloises; Amédée Thierry, Histoire des Gaulois; Jules Michelet, Histoire de France; François Guizot, Du gouvernement représentatif et de l'état actuel de la France; Boulainvilliers, Histoire de l'ancien gouvernement de la France; etc.

15 Olivier-Martin, 1980, p. 71. 
por los miembros de la familia Lebrenn, que han ido pasando de generación en generación, y que narran los hechos históricos que vivieron, preservando así el recuerdo de la tradición familiar. Además de los manuscritos, cada uno de los muchos Lebrenn que desfilan por las páginas de Les mystères du peuple dejó como recuerdo de su biografía particular un objeto simbólico que acredita su participación en la pequeña historia rebelde del pueblo. Estos objetos dan título a los libros y capítulos que componen la obra. Por medio de este artificio literario, Sue quiere dar validez documental a las vivencias de los franceses de clase popular, la Francia oprimida, utilizando los mismos recursos que se usan para la construcción del relato histórico oficial: textos escritos y cultura material.

Son muchas las lecturas que permite la obra, pero aquí nos centraremos en tres aspectos que constituyen la clave para explicar la importancia de esta novela en la difusión de una forma distinta (frente a la historia oficial) de entender, historiográfica y literariamente, la evolución de Francia como nación en la cultura política del socialismo premarxista francés ${ }^{16}$. Se trata, en primer lugar, de la dualidad étnica entre galos y francos (pilar de una interpretación nacionalista del pasado); en segundo lugar, del papel de la rebeldía y la insurrección como instrumentos de transformación social (base de la propuesta revolucionaria de una parte del socialismo utópico); y, por último y más brevemente, del significado de un espiritualismo alternativo que sirviera de fundamento a un nuevo orden moral ${ }^{17}$.

\section{La irreductible aldea gala}

Los desposeídos de Les mystères de Paris o los marginados de Le Juif errant se transmutan en Les mystères du peuple en unos orgullosos galos que, a pesar de su atribulada historia y salvo momentos puntuales, no son unos pobres desvalidos a la busca de un redentor, sino la representación de la Francia oprimida, pero fuertemente concienciada de su condición de

${ }^{16}$ En este texto se utilizarán las expresiones «socialismo premarxista» y «socialismo utópico» en su sentido convencional, a pesar de que, dada la gran diversidad de posiciones políticas y sociales de esta cultura política, sea necesario replantearse el uso de un término tan general. Véase al respecto Brémand, 2014.

${ }_{17}$ En este trabajo se ha utilizado la primera edición de la obra: Les mystères du peuple, ou Histoire d'une famille de prolétaires à travers les âges, Paris, Administration de la librairie, 1849-1857, 16 vols. 
pueblo libre. Los galos son en esta novela el pueblo originario, la verdadera y auténtica Francia. Desde un primer momento, Sue nos pone en antecedentes de una realidad que él considera ignorada por muchos franceses de su tiempo, una realidad que le sirve de base en la construcción de una narrativa republicana sobre el pasado nacional. En las primeras páginas de la novela, y con intención pedagógica, Sue describe una conversación entre dos personajes mediante la cual uno de ellos explica cómo ha sido ocultada a los franceses su verdadera historia, sus orígenes. El lector conocerá esta realidad a través de la familia Lebrenn, procedente de Bretaña. Resulta curioso, a este respecto, que esta familia, a la que se nos presenta como modelo moral y político de la Francia esencial, proceda, precisamente, de la región que en la época en la que se publicó la novela era tenida por la zona más católica y conservadora del país ${ }^{18}$. La intención del autor, con toda probabilidad, era mostrar el carácter impuesto de una religión y un pensamiento político «no natural» al pueblo galo. Los Lebrenn encarnan los rasgos ideales del carácter nacional francés (bretón de origen): valor, honestidad, pureza de espíritu, fuerte moralidad y gran capacidad de trabajo. A ello se une un aspecto físico que remite también a la idealización del galo: alta estatura, pelo de color rubio, ojos claros y una fortaleza física que se corresponde con su fortaleza moral. En cierto modo, y en contraste con sus oponentes los francos, esta estrategia responde a una racialización de la virtud en un grupo humano concreto: los galos ${ }^{19}$. Además, en el contexto cultural de su tiempo, Bretaña constituía la reserva espiritual, antropológica y lingüística del celtismo en Francia.

Por otra parte, y políticamente hablando, los Lebrenn compendian la ideología del socialismo no marxista heredero de la revolución de 1789, con sus ideales de igualdad, libertad y fraternidad. Ideales que, literaturizados por Sue, se convierten en principios atemporales que han estado desde siempre en la raíz originaria de la nación francesa. De hecho, la descripción que se nos ofrece de las costumbres galas va en esa línea: un pueblo horizontalmente organizado, con un jefe meramente operativo y elegido por todos; un pueblo libre, unido por lazos étnicos y culturales co-

18 Hay que tener en cuenta que dos grandes personalidades de la cultura católica francesa del XIX se hallaron estrechamente ligadas a Bretaña por nacimiento: Chateaubriand (procedente de Saint-Malo) y Renan (nacido en Tréguier), este último con los matices que cabe hacer con un intelectual crítico ante ciertas posiciones de la Iglesia católica.

${ }^{19}$ Un recurso, la personificación de los valores morales positivos en la familia protagonista, que también utilizó Sue en los Morel de Les mystères de Paris (Pessin, 1992, p. 139). 
munes pues, aunque los Lebrenn proceden de Bretaña, se reconocen en y se unen a los demás galos franceses en momentos críticos como la preparación de la batalla de Morbihan contra los romanos (56 a.C.). En este retrato que hace Sue del pueblo galo se ha querido ver la proyección narrativa del tercer estado descrito por Sieyès en su famoso impreso de $1789^{20}$. Esta identificación tiene todo el sentido por cuanto los galos aparecen como los verdaderos artífices del país, en lo material y en lo espiritual. Los galos, en tanto que encarnación del tercer estado, lo son todo para Francia, como decía Sièyes, han construido el país, a pesar de que no han tenido la menor relevancia política:

...tout ce que constitue la richesse de la France que nos pères avaient reçue des mains de Dieu, nue, inculte et sauvage, ces terres cultivées, ces industries, ces monuments, ces routes, ces canaux [...] ne sont-elles pas le fruit de l'accumulation du travail de nos aïeux, prolétaire et burgeois durant des siècles? Ah! Eux seuls ne sont jamais restés oisifs! Et tandis que les rois, les seigneurs de la conquête franque et le haut clergé catholique, leur éternel et indigne complice, jouissaient dans l'indolence.... ${ }^{21}$.

Derrotados por los romanos debido a la acción de agentes disolventes y traidores, los galos comenzarán un largo periodo de esclavitud, pues tras el yugo romano, vendrá el yugo franco. A este respecto, el doble origen de la nación francesa (franco y galo), consagrado por los historiadores liberales, será desafiado por Sue en su consideración de los francos como pueblo extranjero, germánico, que impuso en Francia sus tradiciones políticas con la implantación de la dinastía merovingia y de la monarquía de Clodoveo, jerarquizando el ejercicio de la autoridad política - a través de la monarquía y la aristocracia - y traicionando la tradición democrática previa $^{22}$. La encarnación literaria de los francos en Les mystères du peuple es Neroweg de Plouernel, el primero de una larga serie de militares, religiosos y aristócratas, que sortearán con éxito las vicisitudes de la historia francesa y que, en la época contemporánea, habrán de adaptarse a las novedades que siguieron a la revolución, entre ellas, la entronización de los Orléans. Los Plouernel representan el principio inmovilista de los privile-

${ }^{20}$ Lévêque, s.f., p. 115.

21 Sue, 1849, I, p. 163.

22 Sue, s.f., III. 
giados. En última instancia, de la aristocracia formada a partir de las hordas bárbaras que llegaron desde Alemania y que se comportaban como los cosaques y los prussiens, coétanos a autor y lectores ${ }^{23}$. Interpretaba Sue aquí, a través de una lectura crítica, ideas difundidas desde finales del siglo XVII y en el XVIII por Henri de Boulainvilliers y los historiadores de la Académie des Belles Lettres acerca del papel de los francos en la formación de una clase aristocrática independiente de la monarquía y frente al pueblo. Boulainvilliers había desarrollado su interpretación histórica del derecho de conquista para justificar los privilegios de la aristocracia, tesis a la que Sue dará la vuelta completamente ${ }^{24}$.

La imposición de los francos sobre los galos tiene, a tenor de lo que se desprende del texto, un cariz si no de exterminio físico, sí de eliminación cultural. De ahí que insista reiteradamente en materias como la descripción de las costumbres de este pueblo, así como de otro elemento sumamente interesante: la cuestión lingüística. También sobre ello Sue divulgaba ideas establecidas por los estudiosos de finales del XVIII, para los cuales la lengua bretona era el origen del resto de las lenguas célticas, idea defendida en especial por Théophile Malo Corret de la Tour d'Auvergne en su libro Origines gauloises (1792-1796) y sintetizadas por lingüistas como Jean François Le Gonidec en su Grammaire Celto-Bretonne (1807). Aunque Sue no planteaba la necesidad de rescatar la antigua lengua bretona (a pesar de que sus héroes la mantienen) reitera la significación de su existencia en el paralelismo que establece entre la costumbre de utilizar los viejos nombres galos y el reverdecer del orgullo nacional bajo la divisa «il nous reste notre nom, notre langue et notre foi». Los descendientes de Joel Lebrenn, el patriarca de la dinastía, utilizaron nombres galos hasta que, esclavizados por los romanos y convertidos en vasallos por los francos, olvidaron sus tradiciones y comenzaron a llamar a sus hijos con nombres latinos o germanos. Cuando, tras la revolución de 1789, renace el orgullo del pueblo, volvemos a ver los viejos nombres en Marik Le-

23 A este respecto, para Sue la dominación romana, a diferencia de la franca, había tenido como aspecto positivo la construcción en la Galia de importantes obras públicas, lo que convertía a los romanos en unos dominadores más tolerables que los francos, raza parasitaria por naturaleza. Es relevante, en el texto de Sue, la insistencia en el valor del trabajo como elemento de validación social de los individuos.

${ }^{24}$ Guiomar, 1992b, p. 63. Las ideas de Boulainvilliers se oponían a las defendidas por François Hotman quien, en su Franco-Gallia (1573), creyó ver en el sentido federativo de los galos y en su monarquía electiva uno de los precedentes de la idea de pacto entre gobernantes y gobernados. 
brenn y sus hijos Sacrovir y Velléda ${ }^{25}$. Por tanto, a lo largo de toda la novela hay una asociación directa entre el olvido de los nombres antiguos y la pérdida de identidad como pueblo, lo que se sustancia de forma muy evidente en la denominación del país, cuyo propio nombre (Galia) es un símbolo de las esencias identitarias de la nación:

Sans doute encore il a été cruel pour nous, conquis, de perdre jusqu'au nom de notre nationalité, de voir imposer à cette antique et illustre Gaule le nom de France, par une horde de conquérants féroces... Aussi, chose remarquable, lors de notre première révolution la réaction contre les souvenirs de la conquête de ces rois de prétendu droit divin, fut si profondément nationale, que des citoyens ont maudit jusqu'au nom Français (et c'était à un certain point de vue aussi logique que patriotique), trouvant odieux et stupide de conserver ce nom au jour de la victoire et après quatorze siècles de lutte contre ces rois et cette race étrangère qui nous l'avaient infligé comme le stigmate de la conquête! ${ }^{12}$.

No fue Sue el único que cantó las ansias de libertad del pueblo galo, pues también se recogieron en una muy conocida canción del poeta más popular de la Francia de la primera mitad de siglo, Pierre Béranger, titulada «Les esclaves gaulois» (1824). Sin embargo, los galos de Béranger son menos rebeldes que los de Sue y más dados a aceptar el doble origen de la nación, como prueba otra de sus canciones, «Les gaulois et les francs», escrita en un momento, 1814, que demandaba la unidad nacional de todos los franceses ante la amenaza extranjera. El interés por los galos, y por el mundo celta en general, se hallaba en el ambiente cultural europeo de la época, sobre todo desde que en 1760 el escocés James Macpherson publicó la recopilación de poemas Fragments of Ancient Poetry Collected in the Highlands of Scotland and Translated from the Gaelic or Erse Language escrita, supuestamente, por un bardo llamado Ossian. El caso de

${ }^{25}$ Sacrovir fue un ciudadano galo-romano (de origen eduo) que encabezó una sublevación fracasada contra el emperador Tiberio en el año 21 . Veleda fue una profetisa de la tribu de los brúcteros muy respetada por las tribus germánicas que luchaban contra los romanos. Apresada por estos, murió en Roma en el año 50. El propio apellido «Lebrenn» hace alusión a Breno, que tras la derrota de los romanos en la batalla de Alia (387 a.C.), obligó a estos a pagarles una gran cantidad de oro para evitar la destrucción de Roma por el ejército galo. Se le atribuye la famosa frase «Vae victis», que alude al hecho de que los vencedores jamás se apiadan de los derrotados.

${ }^{26}$ Sue, 1849, I, pp. 181-182. Según escribe Sue en nota al pie, durante el periodo de la Convención varios diputados pidieron el cambio de nombre del país. 
los poemas del bardo Ossian es una muy interesante muestra de hasta qué punto una construcción cultural más ficticia que real acabó teniendo una impresionante repercusión no solo en la cultura, sino también en la sociedad europea de la época ${ }^{27}$. Los galos, y en general todos los pueblos celtas, constituían un interesante objeto de estudio para la historia, el folklore, la antropología y la lingüística. Revelaban una Europa distinta al mundo clásico, una Europa que permitía explicar la realidad nacional desde un discurso alternativo, que rompiera o matizara la huella dejada en la mayoría de los países europeos por el carácter transnacional de la cultura clásica. En Francia, el interés por la impronta gala en la historia del país se hallaba muy presente, como se ha dicho, en Bretaña, pero también en los círculos celtófilos parisinos. Aunque puede datarse el origen de este interés por el mundo galo en siglos anteriores, el periodo alrededor de la revolución de 1789 fue especialmente fructífero a este respecto, pues algunos de los diputados bretones de orientación girondina (muchos de ellos folkloristas y aficionados a la arqueología) acudieron a la capital y allí entraron en contacto con folkloristas y eruditos de otras regiones de Francia ${ }^{28}$. Uno de los más activos fue Jacques Cambry, autor de dos de los trabajos más significativos del resurgir del celtismo en Francia: Voyage dans le Finistère (1799) y Monuments celtiques, ou recherches sur le culte des pierres (1805). El resultado final de este movimiento fue la creación de la Académie Celtique entre 1804 y 1805 , que si bien no tuvo una actividad de verdadera trascendencia a pesar de la importancia de las personas que formaron parte de ella ${ }^{29}$, institucionalizó el estudio de los restos de los pueblos prerromanos que habitaron lo que hoy conocemos como Francia. La Académie Celtique evolucionó hasta convertirse en 1814 en la Société des Antiquaires de France, que aún existe. Por otra parte, en 1828 aparecieron los tres volúmenes escritos por Amédée Thierry (hermano del también historiador Augustin) bajo el título de Histoire des Gaulois depuis les temps les plus reculés jusqu'à l'entière soumission de la Gaule à la domination romaine,

27 Gaskill, 2004.

28 Guiomar, 1992b. Pomian, 1992.

29 Entre ellos: Jacques-Joseph Champollion-Figeac (hermano del egiptólogo Champollion); el abate Carlo Denina; el general Jean-Joseph Dessoles; el poeta Louis de Fontanes; el escritor y político François de Neufchâteau; Wilhem y Alexander von Humboldt; el biólogo y músico Bernard de Lacépède; el astrónomo Joseph Lalande; el conservador de museos Alexandre Lenoir; el aristócrata François La Rochefoucault, duque de Liancourt; el arqueólogo y botánico Louis-Aubin Millin; el filósofo y escritor conde de Volney; etc. 
más conocido en sus múltiples ediciones como Histoire des Gaulois. Este libro iba a tener gran influencia ya que sentó las bases de la historiografía posrevolucionaria sobre los orígenes galos de Francia a partir de un concepto étnico de la nación ${ }^{30}$. Años después publicó su Histoire de la Gaule sous l'administration romaine (1840-1847). En el ámbito del folklore, fue muy popular la aparición, a cargo de Théodore Hersart de La Villemarqué, de Barzaz Breiz, chants populaires de la Bretagne (1839), que impulsó, no solo un interés por la región, sino también la búsqueda de las raíces de la cultura gala ${ }^{31}$. De forma paralela, y lejos de los entornos académicos, se desarrolló una «celtomanía» en la que se mezclaron la recreación estética, una interpretación muy particular de la cultura céltica y un espiritualismo alternativo que ha llegado a nuestros días a través de variadas y, muy a menudo, excéntricas manifestaciones ${ }^{32}$.

En definitiva, el texto de Sue trasladaba al ámbito de la novela una cuestión, los orígenes celtas de Francia, que llevaba sobrevolando el mundo cultural francés desde el siglo anterior y que a partir de la revolución de 1789 se había politizado extraordinariamente ${ }^{33}$. En la mayoría de las ocasiones, con un sentido nacionalista; en la obra de Sue, con una orientación social muy clara. De tal forma que, si en los galos/proletarios se hallaba el verdadero origen de Francia, los francos/aristócratas no formaban parte del país, eran extranjeros, entes extraños asentados en un territorio al que jamás pertenecieron, por lo que quedaba justificado el derecho a sublevarse contra ellos. El esencialismo de Sue a la hora de entender la historia del país rompía (en el ámbito de la vulgarización, por supuesto) con la teoría historiográfica del doble origen de Francia, que desde la Edad Media y el Renacimiento había venido explicando la formación del reino. La historiografía coetánea siguió manteniendo, no obstante, la teoría del doble origen, gestada entre los siglos medievales bajo la cobertura del origen mítico de ambas etnias. Más aún, al pueblo al que se le atribuyó un origen mítico más tempranamente fue a los francos, pues ya desde el siglo VII existen crónicas que los relacionan con los troyanos, de quienes los francos serían descendientes. Habría que esperar al siglo XV para encontrar algo similar con los

30 Citron, 1991, p. 146. Señala Suzanne Citron que es a Thierry a quien se debe la consagración de Vercingetórix como héroe nacional, mito ampliamente explotado en décadas posteriores.

31 Guiomar, 1992a.

32 Léonard, 2010.

33 Guiomar, 1992b, p. 79. 
galos $^{34}$. Estas fabulaciones medievales tenían por objeto prestigiar a un pueblo, los francos, que necesitaba legitimarse políticamente en el territorio. La historiografía posterior, en particular los historiadores liberales (Guizot, Thierry) interpretaron esa vieja tesis de una forma bastante distinta, defendiendo la idea de que el estado francés moderno había nacido con la conquista franca, a pesar del coste humano de la feudalización ${ }^{35}$. Años después, entre el final del Segundo Imperio y la Tercera República y desde perspectivas nacionalistas, algunos historiadores matizaron la importancia de la huella franca en la historia francesa. El más destacado de ellos fue Fustel de Coulanges, nacido en París, aunque de familia bretona, cuya obra destila un visible antigermanismo marcado por la guerra francoprusiana, como se observa en el análisis que realiza de la herencia política y social de los francos en la historia francesa ${ }^{36}$.

Ni literaria ni historiográficamente estas dualidades acerca del origen de las naciones fueron exclusivas de Francia. En España la cuestión se planteó entre hispanorromanos y visigodos; en Italia entre latinos, por un lado, y lombardos y ostrogodos, por otro; y en Gran Bretaña entre pictos y sajones y, posteriormente, entre sajones y normandos. El caso británico, además, se popularizó muy rápidamente a través de la literatura, en especial por las obras del escritor escocés Walter Scott quien en su Ivanhoe identificó a los normandos como pueblo invasor y a los sajones como los auténticos ingleses (obviando el hecho de que los sajones también eran un pueblo extranjero) ${ }^{37}$.

\section{La revolución liberadora}

El Segundo Imperio no persiguió la obra de Eugène Sue por sus connotaciones nacionalistas. De hecho, a pesar de su admiración por Ju-

${ }^{34}$ Beaune, 1991, pp. 16 y 25-74.

35 Un análisis del tratamiento de la dualidad galos/francos en el mundo intelectual francés en Pomian, 1992. Su repercusión en la construcción de los mitos nacionales en la enseñanza y la historiografía en Citron, 1991, pp. 103-176. El debate sobre los orígenes de la nación (galos, romanos, germanos) en la historiografía francesa desde el siglo XVI, en Nicolet, 2003.

${ }^{36}$ Fustel de Coulanges reinvidicó, sobre todo, la herencia de Roma en la historia y la cultura francesas (Nicolet, 2003, pp. 208-225). Pese a la insistencia en el peso de francos o galos en la formación de la Francia moderna, ya desde la Monarquía de Julio se observa un claro interés en la historiografía por integrar a ambos en un proyecto común que incluyera la revolución de 1789 y la normalizara.

37 Worth, 1995. 
lio César, sobre quien llegó a escribir un libro, Napoleón III impulsó en 1865 una ceremonia de glorificación de Vercingetórix con la instalación de una estatua en Alise-Sainte-Reine, localidad en la que tuvo lugar la batalla de Alésia (52 a.C.) ${ }^{38}$. Lo que le preocupaba al emperador era el espíritu insurreccional que se desprendía de las páginas de Les mystères $d u$ peuple. Como ya se ha visto, en el proceso judicial a la novela se insistió reiteradamente en ello. Por otra parte, Sue jamás ocultó sus intenciones. En la cubierta de todos los volúmenes que forman la obra puede leerse la siguiente frase: «Il n'y a pas une réforme religieuse, politique ou sociale que nos pères n'aient pas été forcés de conquérir de siècle en siècle, aux prix de leur sang, par l'insurrection». Todo el libro, de hecho, puede leerse en clave insurreccional, de oprimidos contra opresores, desde la guerra contra los romanos hasta las guerras de religión, pasando por las revueltas campesinas medievales. «...tôt ou tard, il faut en revenir à cette bonne vieille petite mère, l'insurrection... comme en $89 . .$. comme en $1830 \ldots$ comme demain peut-être», dirá un personaje ${ }^{39}$. En esta dinámica de enfrentamientos seculares, el Sue activista se superpone al analista histórico al presentar de forma maniquea una dualidad entre el bien y el mal encarnados en dos grupos sociales de imposible reconciliación. La razón es clara: la intención del autor era la de hacer pedagogía política a través de la literatura. Para ello, Sue tenía que explicar cómo, desde una utópica edad de oro gala, se había formado un sistema socioeconómico que, apoyado en la esclavitud y el vasallaje, había generado una sociedad desigualitaria y brutal. Es decir, Sue se proponía descubrir dónde estaba el origen del problema de la desigualdad y, como había hecho en sus otras novelas sociales, encontrar la solución al mismo ${ }^{40}$. La descripción de esos gru-

38 En la estatua se incluyeron unas palabras del jefe galo recogidas por César en su Guerra de las Galias: «La Gaule unie, formant une seule nation, animée d'un même esprit, peut défier l'univers». Como ya se dijo, en el siglo XIX Vercingetórix encarnó al héroe nacional por excelencia, aunque fue durante la Tercera República cuando alcanzó una mayor significación por la proyección que sobre él se hizo de los valores morales y políticos republicanos frente a Clodoveo, referente de la Francia monárquica (Amalvi, 1984, p. 306). Las palabras de Vercingetórix tuvieron, después de Sedán, un sentido especialmente importante: la recuperación de la unidad nacional con los territorios perdidos de Alsacia y Lorena. En Les mystères du peuple a Vercingetórix se le llama «le chef des cents vallées», que recorre la Galia para unir a las tribus y formar un ejército con el que enfrentarse a los romanos. Después, bajo la ocupación romana, se le recuerda como un personaje mítico, líder de una epopeya por la libertad y por la nación.

39 Sue, 1849, I, p. 25.

40 Pessin, 1992, p. 130. 
pos sociales enfrentados es fácil de imaginar. Entre los opresores, de origen franco, se hallan los reyes, los aristócratas y los religiosos. A medida que avanza la historia, el autor incluye también a la «tribu mercantile», es decir, a la oligarquía de los negocios y la banca. Los oprimidos presentan un interés mayor pues Sue, como tantos socialistas utópicos de su tiempo, trata de unir en un mismo compromiso a los trabajadores con la pequeña burguesía, propietaria de negocios y motor productivo de la sociedad, pues su condición de individuos autónomos económicamente les permite contemplar la realidad social desde una perspectiva ajena, cultural y socialmente, a todos aquellos que se hallan al límite de la subsistencia. La reivindicación del papel de esa pequeña burguesía emprendedora muestra, a los ojos de Sue y de sus correligionarios, cómo el esfuerzo personal y la confianza en sí mismo puede permitirle al individuo el ascenso social. La familia Lebrenn, que a lo largo de la historia ha pasado por todas las categorías sociales (salvo las asociadas a los privilegiados), es la muestra más evidente de ello. De ahí que corresponda a la clase media el papel tutelar de las clases menesterosas, tanto por lo que respecta a su condición de ciudadanos ejemplares como a su capacidad para ejercer la pedagogía política. Así lo explica Marik Lebrenn:

Voilà le gran mot, des bourgeois républicains socialistes! Voyons, Georges, sérieusement, est-ce que la cause des bourgeois n'est pas liée à celle des prolétaires? Est-ce que moi, par exemple, prolétaire hier, et que le hasar a servi jusqu'ici, je ne peux pas, par un coup de mauvaise fortune, redevenir prolétaire demain, ou mon fils le devenir? Est-ce que moi, comme tous les petits commerçants, nous ne sommes pas à la discrétion des hauts barons des coffre-forts? Est-ce que les petits propiétaires ne sont pas aussi asservis, exploités par ces ducs de l'hypothèque, par ces marquis de l'usure? ${ }^{41}$.

En este sentido, el discurso político que desprende la novela se basa en la idea del progreso continuo de la humanidad (tanto individual como colectivamente) que, a través del esfuerzo personal y de la rebeldía ante la injusticia, camina hacia un punto final: la soberanía del pueblo encarnada en la república democrática. En función de este criterio, el autor lleva a cabo una relectura de la historia de Francia en clave social, otorgando un significado bastante peculiar a algunos episodios históricos como los ba-

${ }^{41}$ Sue, 1849 , I, p. 44-45. 
gaudas durante el Bajo Imperio, el movimiento encabezado por Étienne Marcel para impedir el ascenso al trono de Charles de Valois (en 1357), $\mathrm{o}$ las visiones proféticas de Juana de $\mathrm{Arco}^{42}$. Ese camino continuado hacia el progreso pasa necesariamente por la concienciación de los trabajadores, labor que, como se ha dicho, corresponde a la pequeña burguesía. A este respecto es muy interesante leer cómo narra Sue el paso de los Lebrenn desde su condición de hombres libres a la de esclavos de los romanos, explicando el estado moral de los mismos al señalar que el esclavo, cuando no es maltratado sistemáticamente, acaba perdiendo la conciencia de la libertad inherente al ser humano. El esclavo golpeado mantiene aún, según Sue, una chispa de rebeldía, de conciencia de la injusticia de la que es objeto. Por el contrario, el esclavo domesticado olvida su grandeza como ser humano ${ }^{43}$. Esta reflexión se trasladará después a la condición del vasallo y del trabajador, planteando, muy vagamente, nociones, como la de alienación, que más adelante desarrollará el marxismo bajo otras premisas ideológicas. En la toma de conciencia del oprimido es donde, insiste el autor, hay que encontrar la clave del compromiso entre dos clases que comparten intereses. No hay en Sue, por tanto, la propuesta de crear una sociedad igualitaria, sino de construir un mundo de pequeños propietarios autónomos y de trabajadores concienciados en el que la fraternidad y el sentido de comunidad rijan unas relaciones productivas apoyadas en la inexistencia de conflictos de clase.

Se ha señalado que Eugène Sue descubrió la lucha de clases como herramienta para interpretar la realidad en su novela Le Juif errant (18441845) y que es en Les mystères du peuple donde desarrolló a fondo el concepto, encontrando en el derecho a la insurrección el instrumento de transformación del mundo. De esta forma, Sue habría roto con la lectura que de esa misma realidad había llevado a cabo en Les mystères de Paris,

42 Sue, 1850, IV (bagaudas); s.f., VIII (Étienne Marcel); s.f., IX (Juana de Arco); Juana de Arco es convertida en herö̈ne plébéienne, utilizada por la Iglesia y la aristocracia y víctima de los poderosos.

43 «L'esclave, voué aux plus pénibles labeurs, battu, torturé, retrempe incessamment son énergie dans la douleur, dans la haine; le sentiment de sa dignité n'est pas éteint en lui, car il songe à la révolte! Et cette horreur de l'oppression, seule vertu de l'esclavage, l'esclave amolli, énervé par d'infâmes délices, la perd, cette vertu; et souvent par ses crimes, il égale et dépasse ses maîtres» (Sue, 1850, II, p. 171). Es interesante comparar esta observación con la actitud sumisa de los esclavos galos del poema de Béranger: «Du tyran qui gronde / Prêts à subir la sentence à genoux, / Pauvres Gaulois, sous qui trembla le monde» (Béranger, 1839, II, p. 237). 
donde se recurría a la reconciliación de las diferencias de clase por la vía del ejercicio de la solidaridad y de la beneficencia ${ }^{44}$, solución muy criticada por Marx y Engels en sus comentarios de la novela ${ }^{45}$. En definitiva, y como dice su biógrafo Bory, en Sue es muy perceptible una evolución en su forma de entender el republicanismo socialista partiendo de Les mystères de Paris ${ }^{46}$. Una evolución que parte de un planteamiento basado en la posibilidad de convivencia con el «otro social» hasta la ruptura total entre las clases que vemos en Le Juif errant y en Les mystères du peuple.

El momento más importante en esa recurrencia a la insurrección como mecanismo transformador de las contradicciones sociales es, por supuesto, la revolución de 1789, revolución no finalizada que buscará completarse en 1830 y en 1848. Como no podía ser menos, la «Gran Revolución», como dijera Kropotkin, ocupa en Les mystères du peuple un lugar primordial y en ella Sue nos revela su interpretación de la misma como un proceso traicionado $^{47}$. A la revolución de 1789 consagra el autor su último volumen, titulado Le Sabre d'honneur, en el que se puede apreciar la huella de obras clásicas del pensamiento socialista y del romanticismo social de su tiempo, como la Histoire de la Révolution Française (1847-1862) de Louis Blanc, la Histoire des Girondins (1847), de Alphonse de Lamartine o la Histoire parlementaire de la Révolution Française (1834-1838) de Pierre Buchez. Sue lleva a cabo una lectura jacobina de la revolución que progresivamente va tornando hacia una interpretación socialista de la misma, censurando el discurso liberal y monárquico de 1791 en favor del radical de 1793, que el autor ve reaparecer en 1848, con el fin de avalar la existencia de una tradición republicana en la historia francesa que va desvelándose progresivamente ${ }^{48}$. De esta forma, los conflictos sociales que se plantearon en el periodo revolucionario aparecen como la manifestación más evidente de conflictos similares en otras partes de la novela. Es decir, la lucha entre opresores y oprimidos se reitera históricamente, en su secular camino hacia el progreso continuado de la humanidad. Sue otorga a la revolución un carácter salvífico en el que se mezcla la idea de la justicia social con un cierto humanita-

${ }^{4}$ Eco, 1996, p. 48.

45 Marx y Engels, 1967 (1845), passim, y, especialmente, pp. 228-274.

46 Bory, 1973, pp. 237-250. Le Juif errant plantea, además de las problemáticas sociales habituales en Sue, la cuestión de la intolerancia religiosa.

${ }^{47}$ Un análisis detenido del significado de la revolución francesa de 1789 en la obra de Sue en Garay, 1990.

48 Garay, 1990, p. 756. 
rismo cristiano que lleva a un personaje a hablar de Jesucristo como «le divin prolétaire de Nazareth» y ver en la obra revolucionaria el programa de liberación por el que «...la république a fait en un jour ce que l'Église n'a jamais fait depuis des siècles», haciendo referencia a la obra legislativa de la Convención. Todo ello en un contexto en que las conquistas revolucionarias, nacidas en un contexto nacional francés, son vistas como el germen de la fraternidad universal apoyada en la democracia republicana, pilar para construir la nueva edad de oro de la humanidad: «Je suis donc convaincu que l'avenir appartient forcement à la démocratie, à la république! Je suis donc convaincu qu'un jour on verra les États-Unis de l'Europe» ${ }^{49}$.

Un apartado especialmente importante en la visión que ofrece Sue de la revolución es el dedicado a la figura de Robespierre y a la época del Terror. 1793 constituye, en la mirada del escritor, el momento culminante del proceso, el instante en el que la revolución estaba consolidando sus conquistas, de ahí que niegue la voluntad autoritaria de Robespierre, calificando de fable absurde tal aseveración. La dictadura, ejercida involuntariamente por un hombre íntegro, era necesaria para mantener un proceso amenazado desde dentro y desde fuera. Era el único camino posible para evitar el fracaso ante los crímenes de los convencionales Tallien, Fouché o Fréron, entre otros. En un texto encontrado entre sus papeles de Annecy, en el que comentaba el proceso verbal de la sesión de la Convención del 9 de termidor, incidía en esta cuestión, tratando de lavar la imagen de Robespierre como dictador y de 1793 como la infamia de la revolución. Sus palabras explican con claridad sus ideas al respecto:

Les meneurs de la Révolution de thermidor ont été les membres les plus scélérats de la Convention, et les Martyrs de cette Révolution ont été les citoyens les plus purs, les plus irréprochables de la Représentation nationale. Non seulement Robespierre n'a pas voulu la prolongation de la terreur, mais il a été envoyé à l'échafaud parce qu'il voulait mettre fin à la terreur devenue non seulement atroce, mais absurde, mais impolitique depuis qu'elle n'était plus impérieusement commandée par la Défense de la République, de la Révolution et de la France, attaquée au-dehors par l'Europe coalisée contre elle et déchirée au-dedans par la guerre civile qui ensanglantait les trois quarts de nos provinces ${ }^{50}$.

\footnotetext{
49 Sue, 1857, XVI, pp. 72 y 94.

50 Texto reproducido en Nicolas, 1962, pp. 80-81. Cursivas en el original. Este texto está fechado el 10 de junio de 1857.
} 
La figura de Robespierre y los sucesos de 1793 han sido siempre uno de los temas más problemáticos de la Revolución francesa, no solo para la historiografía, sino también la literatura ${ }^{51}$. Los contemporáneos de Sue no se mostraron unánimes al respecto. La historiografía liberal (Mignet, Thiers, Michelet) fue muy crítica con un periodo que, desde su perspectiva, sacrificó los logros revolucionarios a la consecución de unos fines alejados de las conquistas del liberalismo. Sue, sin embargo, se posicionó del mismo lado que una buena parte de la historiografía socialista y republicana de izquierdas, al reivindicar a Robespierre como el guardián de las esencias revolucionarias, llamándole «l'immortel martyr». Será precisamente la historiografía republicana la que trate de reconstruir la imagen del Incorruptible a través de nuevo material documental, de fuentes históricas que, además de releer la obra del personaje, permitían rescatar la herencia de la revolución en el contexto de la monarquía de los Orléans y, posteriormente, de Napoléon III ${ }^{52}$. Sue se situaba, en este sentido, al lado de Philippe Buonarroti, Louis Blanc, Guillaume Lallement o Albert Laponneraye, editor de las Oeuvres de Maximilien Robespierre (1840). En definitiva, desde la perspectiva de Sue, la reacción termidoriana representa la traición a la revolución por parte de las fuerzas tradicionales e inmovilistas escudadas en los propios revolucionarios. A partir de ese momento, comenzó para Francia el camino que condujo a la dictadura militar de Bonaparte. Establece aquí nuestro autor un paralelismo entre este periodo y la situación del país entre 1848 y 1851 , con una nueva revolución traicionada por los propios revolucionarios (Louis Napoléon Bonaparte, en este segundo caso) apoyados por las fuerzas de la reacción (Iglesia y aristocracia). Tal vez nada defina mejor la problemática identificación que hace Sue entre el Terror y el mantenimiento de los principios de la revolución que el diálogo que mantienen dos personajes de Quatrevingt-treize, de Hugo, cuando uno de ellos dice: «Un jour, la révolution sera la justification de la Terreur» y el otro le responde: «Craignez que la Terreur ne soit pas la calomnie de la révolution» ${ }^{53}$.

51 Belissa y Bosc, 2013.

52 Belissa y Bosc, 2013, pp. 14 y 21. Se hace referencia a documentos como los discursos de Robespierre, los Papiers inédits trouvés chez Robespierre, Saint-Just, Payan, etc. précédés du Rapport fait au nom de la Commission chargée de l'examen des papiers de Robespierre (1828), las Mémoires de Charlotte Robespierre sur ses deux frères (1835) o las Mémoires authentiques de Maximilien de Robespierre (1830).

${ }^{53}$ Hugo, 1924, p. 291. Quatrevingt-treize, cuya primera edición es de 1874, debe leerse a la luz de los acontecimientos de la Comuna de París de 1871. 


\section{Anticlericalismo cristiano y espiritualismo galo}

Les mystères du peuple destilan un fuerte anticlericalismo, lo que no significa que no haya en la obra un sentido religioso y espiritual bastante marcado ${ }^{54}$. Los ministros de la Iglesia forman parte de la élite parasitaria y a ellos atribuye Sue una gran capacidad para crear disensiones en la comunidad, cargando las tintas en los jesuitas, a quienes atribuye desde la legislación educativa del ministro Falloux (1850) hasta los planes conspirativos para acabar con la libertad en distintas épocas de la historia de Francia ${ }^{55}$. También en esta cuestión hay un cambio desde Les mystères de Paris a Le Juif errant y Les mystères du peuple, novelas manifiestamente anticlericales. En las dos últimas los religiosos son los principales agentes disolventes de la armonía social, creadores de conflictos entre los ciudadanos para su propio beneficio. Frente a ellos, opone Sue a Jesucristo, que aparece en Les mystères du peuple como el primer sans culotte. De hecho, hay una explícita identificación entre el mensaje de Cristo y el mensaje de la revolución:

Christ, le divin prolétaire de Nazareth, avait dit: Les fers des esclaves seront brisés; tous les hommes seront unis dans une fraternelle égalité; les pauvres, les veuves et les orphelins seront secourus. Voilà ce que Jésus, le charpentier de Galilée, l'obscur artisan, avait prophétisé... [...] C'est la révolution, c'est la république. En un jour, elle a réalisé la prophétie de Christ, méconnue par ses prêtres depuis dix-huit cents ans. Oui, vasselage et servage ont été abolis par la révolution, en $1789^{56}$.

El mensaje del socialismo cristiano, que se halla muy presente en otros republicanos radicales ${ }^{57}$, se completa en el ámbito espiritual con el

54 Como se dijo con anterioridad, este apartado será más breve que los anteriores, pues un análisis más detallado obligaría a extenderse en la forma en la que el autor reconstruye las antiguas creencias y los arcaicos rituales religiosos galos (como las procesiones y ceremonias en los espacios de culto celta) y los incorpora a su discurso otorgándoles un significado propio.

${ }^{55}$ La conspiración jesuítica para acabar con el progreso y las libertades narrada por Sue en Les mystères du peuple fue retomada por Maurice Joly en su Dialogue aux enfers entre Machiavel et Montesquieu (1864) con el propósito de atacar a Napoleón III. De Joly tomó la policía zarista la idea aplicándola a los judíos, dando como resultado el mito de la gran conspiración judía mundial de Los protocolos de los sabios de Sión (Eco, 1996, pp. 148-150).

56 Sue, 1857, XVI, pp. 71-72.

57 Las interpretaciones de la figura de Cristo en este contexto en Bowman, 2016. 
rescate de la antigua religión de los pueblos de la Galia, mantenida por la familia Lebrenn en privado y que se convierte, al igual que la lengua, en otro elemento identitario de la Francia verdadera. Una religión pagana, apoyada en los antiguos dioses, la creencia en la vida después de la muerte y en prácticas como la peregrinación a los alineamientos de Carnac. Es curioso, a este respecto, cómo Sue describe la creencia de los galos en la reencarnación, atribuyendo a los druidas un papel clave en la interpretación de la misma, en un contexto en el que las doctrinas espiritistas ganaban adeptos en determinados círculos ${ }^{58}$.

En la novela, la religión tiene una funcionalidad muy clara. A través del paganismo galo, y sirviéndose de los recursos efectistas de la literatura popular, Sue puede introducir en la trama elementos mesiánicos sobre la gran epopeya revolucionaria, profetizada por varios personajes a lo largo de la historia. Aquí juegan un papel muy destacado las mujeres de la familia Lebrenn, que actúan, a lo largo de los siglos, como las portadoras del mensaje liberador (a través de sus visiones y profecías) acerca de la victoria final del proyecto humanitario y fraternal de la democracia republicana. En líneas generales, las mujeres de la novela se adecuan al estereotipo femenino de la época como madres y esposas, transmisoras de los valores de la comunidad ancestral y pilares de la familia. Ello no es obstáculo para que, en la denuncia de las injusticias de la sociedad industrial, no se olviden los abusos sobre las mujeres trabajadoras: «...filles, esclaves de certains fabricants, forcées à choisir entre le déshonneur et le chômage». Para describir a las mujeres galas, y de nuevo jugando con la fluidez de las fronteras entre historia y literatura, Sue se remite a los testimonios de Estrabón y Diodoro de Sicilia para destacar de ellas su apostura física y su fertilidad ${ }^{59}$. Sin embargo, y en el caso de las que adquie-

58 Un ejemplo de estas creencias: «...à l'autre côté de ce rideau qui, pendant la première période de notre vie ici-bas, nous cache les merveilleux, les éblouissants mystères de nos existences futures, existences infinies, variées, comme la puissance divine dont elles émanent. En un mot, nous ce cessons pas de vivre: nous allons vivre ailleurs, dans des pays inconnus... voilà tout» (Sue, 1849, I, p. 96). Como en otras ocasiones, Sue respalda sus palabras con textos académicos. En este caso, el de su amigo el saintsimoniano Jean Reynaud, autor de la entrada «Druidisme» en el volume 4..$^{\circ}$ de la Encyclopédie nouvelle: Dictionnaire philosophique, scientifique, littéraire et industriel, que dirigió junto a Pierre Léroux entre 1839 y 1847.

59 «Les femmes de la Gaule ne rivalisent pas seulement avec les hommes par la grandeur de leur taille, elles les égalent aussi par la force de l'âme» (Diodoro de Sicilia); «Les Gauloises sont fécondes et bonnes éducatrices» (Sue, 1849, I, p. 83). 
ren un papel destacado, el rol tradicional se subvierte al adquirir algunos personajes femeninos, y en determinados momentos históricos un protagonismo que sirve de revulsivo para la concienciación de los demás personajes. Algunas de ellas, incluso, acaban inmoladas como heroínas en aras de la supervivencia de la comunidad, como sucede con la hija del patriarca de la dinastía de los Lebrenn, la sacerdotisa Hena, muerta en un ritual sacrificial para propiciar el éxito de los galos en la guerra contra los romanos. Tal vez la más destacada de estas mujeres sea el personaje de Victoria, cuyo nombre es muy revelador. Víctima de los abusos la monarquía absoluta, Victoria morirá combatiendo en las jornadas revolucionarias de 1789, no sin antes vaticinar un futuro prometedor para la causa revolucionaria: «Je prophétise la république universelle ${ }^{60}$. De este modo, la lucha política por la república democrática universal se convierte en lucha sagrada, en misión divina. En palabras de uno de los protagonistas: «elle [la república democrática universal] est marquée dans les destinées de l'humanité en vertu de la loi divine du progres» ${ }^{61}$.

\section{Conclusión: el eco de los misterios}

En sus recuerdos de 1848, Tocqueville comentaba los parecidos entre una novela y un motín, diciendo que lo más difícil en ambos casos era cómo cerrar la trama ${ }^{62}$. Y ese problema es más que evidente en Les mystères du peuple. Su bastante inverosímil final consiste en que la familia Lebrenn, a punto de ser apresada por el gobierno de la revolución traicionada en 1851, huye de Francia acompañada de otros personajes de la literatura de Sue, como Rodolphe de Gerolstein (Les mystères de Paris) y los protagonistas de Le Juif errant y Martin, l'enfant trouvé. Todos ellos encontrarán su nuevo destino en América, a la que llegarán en un barco cuyo nombre no podía ser otro que «La République universelle». Más allá de las debilidades que presenta esta novela en materia de construcción literaria, producto del género al que se adscribe y de las condiciones de su redacción, lo interesante de ella es la forma en la que contribuyó a la vulgarización de las tesis del republicanismo socialista con el que el autor simpatizaba ${ }^{63}$. Sue llegó

\footnotetext{
60 Sue, 1857, XVI, p. 57.

61 Sue, 1857, XVI, p. 390.

62 Tocqueville, 1994, 73.

63 Lévêque, s.f., pp. 113-114.
} 
con su novela adonde no llegaban los historiadores socialistas, rompiendo el consenso liberal sobre la historia nacional entendida como el compromiso secular entre las dos Francias y presentando la revolución de 1789 como el momento de la revancha de la verdadera Francia, la Francia gala, la Francia popular. El carácter artificioso y, a la vez, sentimental de sus novelas sociales producía un efecto emocional en sus lectores que conducía a la aceptación casi inconsciente del mensaje político subyacente. Gracias a ello, Sue contribuyó extraordinariamente a consolidar en el imaginario político francés del siglo XIX un concepto progresista de Francia que se apoyaba en tres referentes: Galia, República y Nación. Galia aludía a la herencia étnico-cultural del país; República a la forma democrática de gobierno; y Nación a la comunidad de ciudadanos consolidada alrededor de los valores laicos que la daban sentido. Frente él se hallaba la otra trinidad que, defendida por la cultura política conservadora, se basaba en el lema Francia-Monarquía-Catolicismo $^{64}$.

La incorporación de estos conceptos políticos progresistas a la imagen del país se afirmó durante la Tercera República y se manifestó de forma muy evidente con la generalización del uso de la expresión «nos ancêtres les gaulois» ${ }^{65}$. Es cierto que fue necesario incorporar al discurso nacionalista los avances de la historiografía y la arqueología, que mostraban la necesidad de actualizar o relativizar ese pasado galo tan remoto y primitivo. Si bien en literatura los tiempos de la novela sentimental y folletinesca habían pasado y ya no quedaba lugar para los melodramas de Sue, la enseñanza de la historia seguía basándose en el esencialismo nacionalista. Ernest Lavisse, autor de varios manuales escolares que se utilizaron en Francia hasta bien entrado el siglo Xx, es un buen ejemplo de cómo, sin descartar la existencia intemporal de la nación gala, se podía incorporar a los pueblos que llegaron posteriormente al país. Al inicio de su Cours élémentaire escribía Lavisse: "Autrefois notre pays s'appelait la Gaule, et les habitants s'appelaient les Gaulois. Notre pays a bien changé depuis lors, et nous ne ressemblons plus guère à nos pères les Gaulois», para decir después que «Dans la suite, la Gaule changea de nom. Elle s'appela la France». A través de este concepto de «nación acumulativa», no se perdía la versatilidad política de los héroes nacionales y más en un contexto, principios del siglo Xx (cuando se publicó el libro), en que el naciona-

${ }^{64}$ Amalvi, 1984, p. 303.
65 Burguière, 2003, pp. 44 y 52. 
lismo cobraba impulso. Así, no es de extrañar que Lavisse recordara a los niños franceses que Vercingetórix murió "pour défendre la patrie» ${ }^{66}$, algo con lo que Eugène Sue habría estado completamente de acuerdo.

\section{Bibliografía}

Amalvi, Christian, «De Vercingétorix à Astérix, de la Gaule à De Gaulle, ou les métamorphoses idéologiques et culturelles de nos origines nationales», Dialogues d'histoire ancienne, vol. 10, 1984, pp. 285-318.

Amalvi, Christian, «Le baptême de Clovis: heurs et malheurs d'un mythe fondateur de la France contemporaine, 1814-1914», Bibliothèque de l'École des Chartes, tome 147, 1989, pp. 583-610.

BEaune, Colette, Naissance de la nation France, Gallimard, París, 1991.

BELISSA, Marc y Bosc, Yannick, Robespierre. La fabrication d'un mythe, Ellipses, París, 2013.

BÉNICHOU, Paul, La coronación del escritor, 1750-1850. Ensayo sobre el advenimiento de un poder espiritual en la Francia moderna, F.C.E., México, 1981.

BéRAnger, Pierre, Oeuvres complètes de Béranger, H. Fournier, París, 1839, vols. I y II.

Bory, Jean-Louis, Eugène Sue . Dandy et socialiste, Hachette, París, 1973.

Bowman, Frank-Paul, Le Christ des barricades, 1789-1848, Le Cerf, París, 2016 (1987).

BRÉMAND, Nathalie, «Introduction: 'Socialistes utopiques', les mal-nommés», Cahiers d'histoire. Revue d'histoire critique, n. ${ }^{\circ}$ 124, 2014, pp. 13-24.

BURDIEL, Isabel y SERNA, Justo, Literatura e historia cultural o por qué los historiadores deberíamos leer novelas, Episteme, Valencia, 1996.

BurguiÈRE, André, «L'historiographie des origines de la France: genèse d'un imaginaire national», Annales. Histoire, Sciences sociales, n. ${ }^{\circ}$ 1, 2003, pp. 41-62.

CAHEN, Jacquelin, «Les premiers éditeurs de Marx et Engels en France (18801901)», Cahiers d'Histoire. Revue d'histoire critique, n. ${ }^{\circ}$ 114, 2011, pp. 20-37.

Charle, Christophe, «Méthodes historiques et méthodes littéraires, pour un usage croisé», Romantisme. Revue du Dix-neuvième siècle, n. ${ }^{\circ}$ 143, 2009, pp. 13-29.

Citron, Suzanne, Le mythe national: l'histoire de France en question, Éditions Ouvrières, París, 1991.

${ }^{66}$ Lavisse, 1913, pp. 1, 7 y 182. Citron, 1991, pp. 43-44. 
DuboIs, Claude-Gilbert, «Nos ancêtres les Gaulois: un élément de construction identitaire devenu stéréotype», en KOHLER, F. (dir.), Stéréotypes culturels et constructions identitaires, Presses universitaires François Rabelais, Tours, 2007.

EcO, Umberto, El superhombre de masas: retórica e ideología en la novela popular, Lumen, Barcelona, 1995.

Eco, Umberto, Seis paseos por los bosques narrativos, Lumen, Barcelona, 1996.

GARAY, Bernard, «La Révolution dans Les mystères du peuple d'Eugène Sue», Revue d'Histoire littéraire de la France, n. ${ }^{\circ}$ 4/5, 1990, pp. 748-764.

Garay, Bernard, Eugène Sue. De l'illusion lyrique de 1848 au roman national, Nancy: Université de Nancy, 2021 (1992) https://hal.archives-ouvertes.fr/ hal-02974362

GaskiLl, Howard (ed.), The Reception of Ossian in Europe, Continuum, Londres, 2004.

GAUDIN, François, Maurice Lachâtre, éditeur socialiste (1814-1900), LambertLucas, Limoges, 2014.

Guiomar, Jean-Yves, «Le Barzaz-Breiz de Th. H. de La Villemarqué», en NorA, P., Les Lieux de mémoire, III-2, Gallimard, París, 1992a, pp. 526-565.

Guiomar, Jean-Yves, «La Révolution Française et les origines celtiques de la France», Annales historiques de la Révolution française, n. ${ }^{\circ} 287,1992 \mathrm{~b}$, pp. 63-85.

Hartog, François, Le XIXe siècle et l'histoire: le cas Fustel de Coulanges, Éditions du Seuil, París, 2001 (1988).

Hugo, Victor, Quatrevingt-treize, Ollendorf, París, 1924 (1874).

LAVISSE, Ernest, Histoire de France. Cours élémentaire, Armand Colin, París, 1913.

LÉONARD, Alexis, «Nos ancêtres les Gaulois: la celtomanie en France», en BuRLE-ErRecade, É. y Naudet, V. (dir.), Fantasmagories du Moyen Âge. Entre médiéval et moyen-âgeux, Publications de 1'Université de Provence, Aix-enProvence, 2010.

LÉVÊQUE, Laure, «Les Mystères du peuple d'Eugène Sue, une politique fiction de 1848: de quoi demain sera-t-il fait?», Babel, n. . 30, 2014, pp. 37-67.

LÉVÊQUE, Laure, «Les mystères du peuple d'Eugène Sue, une guerre des Gaules du XIX ${ }^{e}$ siècle: de la minorité culturelle à l'hégémonie identitaire», http://dspace.uni.lodz.pl:8080/xmlui/handle/11089/24070, http://dx.doi. org/10.18778/8088-896-8.11

LiLlo, Alejandro, «La literatura de ficción como fuente histórica», Studia historica. Historia contemporánea, n. ${ }^{\circ} 35,2017$, pp. 267-288.

LyON-CAEN, Judith, La Lecture et la vie. Les usages du roman au temps de Balzac, Tallandier, París, 2006.

LyOn-CAEn, Judith (ed.), Eugène Sue, Les Mystères de Paris, Gallimard, París, 2009.

LyON-CAEN, Judith y RIBARD, Dinah, L'Historien et la littérature, La Découverte, París, 2010. 
Nuestros ancestros los galos. Eugène Sue y los misterios del pueblo francés

Lyons, Martin, «Les best-sellers», en ChARTIER, R. y MARTin, H.-J. (dirs.), Histoire de l'édition française. Le temps des éditeurs. Du romantisme à la Belle Époque, Fayard, París, 1990, pp. 409-437.

MARX, Karl y EnGELS, Friedrich, La sagrada familia, Grijalbo, México, 1967.

Nicolas, Jean, «Eugène Sue robespierriste», Annales Historiques de la Révolution Française, tome 37, 1965, pp. 79-82.

Nicolet, Claude, La fabrique d'une nation. La France entre Rome et les Germains, Perrin, París, 2003.

Olivier-MARTIN, Yves, Histoire du roman populaire en France de 1840 à 1980, Albin Michel, París, 1980.

PESSIN, Alain, Le mythe du peuple et la société française du XIXe siècle, Presses Universitaires de France, París, 1992.

Pierrat, Emmanuel, Accusés Baudelaire, Flaubert, levez-vous!, André Versaille éditeur, París, 2010.

Pomian, Krzysztof, «Francs et Gaulois», en NorA, P. (dir.), Les lieux de mémoire. Les France, III-1, Gallimard, París, 1992, pp. 40-105.

SuE, Eugène, Les mystères de Paris, C. Gosselin, París, 1842-1843, 5 vols.

SuE, Eugène, Le juif errant, Paulin, París, 1844-1845, 10 vols.

SuE, Eugène, Les mystères du peuple, ou Histoire d'une famille de prolétaires à travers les âges, Administration de la librairie, París, 1849-1857, 16 vols.

THIESSE, Anne-Marie, «L'éducation sociale d'un romancier», Actes de la recherche en sciences sociales, vol. 32-33, 1980, pp. 51-63.

Thiesse, Anne-Marie, «Le roman populaire», en ChARTIER, R. y MARTIN, H.-J. (dirs.), Histoire de l'édition française. Le temps des éditeurs. Du romantisme à la Belle Époque, Fayard, París, 1990, pp. 509-518.

THIESSE, Anne-Marie, La creación de las identidades nacionales. Europa: siglos XVIII-XX, Ézaro, Madrid, 2010.

ToCQueVILle, Alexis, Recuerdos de la revolución de 1848, Trotta-Comunidad de Madrid, Madrid, 1994.

WAUTIER D'HaLluVIN, Édouard, Eugène Sue, auteur des «Mystères du peuple», à la barre de l'histoire. Jury, le Peuple, Dentu, París, 1851.

WorTH, Chris, «Ivanhoe and the Making of Britain», Links \& Letters, n. ${ }^{\circ}$ 2, 1995 , pp. 63-76.

\section{Datos de la autora}

Raquel Sánchez doctora en Historia y en Filología Hispánica, Catedrática de la Facultad de Geografía e Historia de la Universidad Complutense (Departamento de Historia Moderna e Historia Contemporánea). Su labor investigadora se ha desarrollado en dos áreas: la historia política y la historia de la cultura europea y española. Se ha especializado en las relaciones entre política y cultura entre el siglo XIX y la primera parte del siglo XX, así como en el estudio del proceso de pro- 
fesionalización del creador literario y artístico y su proyección en el espacio público a lo largo de este periodo. Asimismo, ha trabajado sobre la configuración del estado liberal en España, los planteamientos políticos del liberalismo conservador y los procesos de nacionalización en la España del siglo XIX.

Algunos de sus trabajos son: Mediaciones y transferencias culturales. Eugenio de Ochoa y las letras europeas (2017), La historia imaginada. La Guerra de la Independencia en la literatura española (2008), El autor en España, 1900-1936 (2008), Alcalá Galiano y el liberalismo español (2005) y Románticos españoles (2006). 